\title{
Coronary artery bypass grafting in the awake patient: Three years' experience in 137 patients
}

\author{
Haldun Y. Karagoz, MD \\ Murat Kurtoglu, MDa \\ Beyhan Bakkaloglu, MD \\ Beril Sonmez, $M D^{\mathrm{b}}$ \\ Taner Cetintas, $\mathrm{MD}^{\mathrm{a}}$ \\ Kemal Bayazit, $\mathrm{MD}^{\mathrm{a}}$
}

See related articles on pages 1204, 1394, and 1526.
From the Departments of Cardiovascular Surgery ${ }^{\mathrm{a}}$ and Cardiovascular Anesthesiolo-

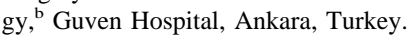

Received for publication April 19, 2002; revisions requested June 13, 2002; revisions received June 15, 2002; accepted for publication June 27, 2002.

Address for reprints: Haldun Y. Karagoz, MD, Department of Cardiovascular Surgery, Guven Hospital, Simsek Sok 29, Ayranci, Ankara 06450, Turkey (E-mail: karagoz@tr.net).

J Thorac Cardiovasc Surg 2003;125:1401-4

Copyright $\odot 2003$ by The American Association for Thoracic Surgery

$0022-5223 / 2003 \$ 30.00+0$

doi:10.1016/S0022-5223(02)73268-6
Objective: Our experience with 137 patients operated on without general anesthesia is reviewed to explore the validity of our surgical strategy.

Methods: Between October 1998 and January 2002, 137 patients underwent coronary artery bypass grafting with high thoracic epidural anesthesia. There were 47 female and 90 male patients, ranging in age from 37 to 92 years (mean, $68 \pm 12$ years). Two patients underwent reoperation. Nineteen patients had contraindications for general anesthesia. Target vessels involved were the left anterior descending artery in 122 , the right coronary artery in 6 , the left anterior descending artery plus right coronary artery in 7 , and the left anterior descending artery plus circumflex artery in 2 patients. Coronary artery bypass was performed through limited access in 74 patients (H-graft in 42 and rib cage lifting in 32 patients) and through a median sternotomy in 63 patients. Cardiopulmonary bypass was not used.

Results: In 39 (28.4\%) patients pneumothorax was observed during surgical intervention. There was no mortality. Of the 137 patients, 132 (96.3\%) completed the procedure awake. In 58 patients the intensive care unit was not used. Eight patients were discharged from the hospital on the day of their operation. Mean length of hospitalization was 1 day (range, 0-3 days). One hundred thirty-one patients were followed up for a period of 3 months and 3 years after their operations, and 94.7\% of the patients were symptom free. Control angiograms were obtained in 41 patients. Graft patency was $100 \%$, with one radial artery graft spasm.

Conclusions: Our initial experience confirms the feasibility and safety of performing coronary artery bypass grafting in the conscious patient without general anesthesia. Further study is required to define the possible extent and limitations of this strategy.

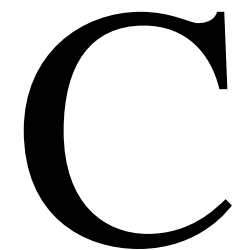
oronary artery bypass grafting (CABG) in an awake patient without endotracheal general anesthesia was first performed in October 1998 with high thoracic epidural block. ${ }^{1}$ Since then, similar cases had been reported in the literature in an attempt to decrease the invasiveness of the CABG procedure. ${ }^{2-7}$ This report presents our experience in 137 patients in whom this procedure was performed during a time period of 3 years.

\section{Patients and Methods}

Between October 1998 and January 2002, 137 patients underwent CABG with high thoracic epidural anesthesia. Placement of an epidural catheter was not possible in 4 patients, and they are not included in this series of patients.

Patient selection criteria included the absence of recent antithrombotic $(<1$ week) or fibrinolytic therapy ( $<2$ days), good-caliber target vessels, the presence of an inflow graft (internal thoracic artery [ITA]), and patient cooperation. Severe left ventricular dysfunction, 
severe pulmonary disease, or any other variable that could present potential comorbidity did not affect patient selection. Written informed consent was obtained from every patient. There were 47 female and 90 male patients, ranging in age from 37 to 92 years (mean age, $68 \pm 12$ years). Two patients underwent reoperation with previous vein grafts to the left anterior descending artery (LAD). In 19 patients various contraindications to general anesthesia was present: end-stage liver disease in 9, end-stage pulmonary disease in 8 , and mechanical obstructions to endotracheal intubation in 2 patients. In patients with a mechanical obstruction to endotracheal intubation, a percutaneous tracheotomy kit (Portex, Berck Sur Mer, France) was kept on standby in case conversion to general anesthesia should be required. In 118 awake patients CABG was used electively (ie, these patients could be operated on by using conventional techniques as well). In 26 of these patients, this strategy was used by physician preference because of multiple comorbidities, and in 92 patients patient preference was the case. Twenty-nine of these patients were operated on in lieu of primary percutaneous revascularization procedures.

A $0.07-\mathrm{mg} / \mathrm{kg}$ dose of midazolam was used for premedication. Except for this, perioperative sedation was not used. At least 60 minutes elapsed between epidural catheter insertion and heparinization. The objective of epidural anesthesia was to achieve somatosensory and motor block at the T1-T8 level. The upper permissible level of block was C6, which was monitored by the development of Horner syndrome. One of the major objectives was to achieve motor block of the intercostal muscles while preserving diaphragmatic respiration.

The patient was placed in a sitting position, and a 16-gauge flexible-tip catheter (Perifix Soft 505, B. Braun, Germany) was inserted through a Tuohy needle at the T1-T2, T2-T3, or T3-T4 intercostal space by using the median approach and the loss-ofresistance or hanging drop technique. The catheter was directed cephaled and advanced 3 to $4 \mathrm{~cm}$ into the epidural space. The block level was tested after epidural administration of a test dose of $5 \mathrm{~mL}$ of lidocaine (2\%). An epidural anesthesia solution was used for epidural anesthesia, consisting of bupivacaine hydrochloride, lidocaine, fentanyl, and bicarbonate in a previously described composition. ${ }^{1}$ In the operating room $10 \mathrm{~mL}$ of epidural anesthesia solution was administered epidurally as a bolus, and the level of the block was tested by assessing both temperature and pinprick discrimination. Loss of temperature discrimination was deemed necessary to continue the operation with epidural anesthesia. Additional doses of epidural anesthetic solution were administered as a bolus or continuous infusion as needed to achieve motor block of the intercostal muscles. Motor block of the intercostal muscles was assessed visually by monitoring the loss of intercostal movement. Sensory block level was maintained at the C6-T8 level.

No muscle-paralyzing agent or general anesthetic agent was used. Throughout the operation, patients spontaneously breathed room air or nasal oxygen. The epidural catheter was removed a few hours after the operation.

Target vessels involved were the LAD in 122, right coronary artery (RCA) in 6, LAD plus RCA in 7, and LAD plus circumflex coronary artery in 2 patients. CABG was performed through limited access in 74 patients. Among these patients, the H-graft technique was used to revascularize the LAD in 36 patients and the RCA in 6 patients by using previously described techniques. ${ }^{1,8,9} \mathrm{~A}$

\section{TABLE 1. Perioperative variables}

\begin{tabular}{lc}
\hline $\mathrm{SV}_{2}(\%)$ & $94 \pm 0.8$ \\
$\mathrm{PCO}_{2}(\mathrm{~mm} \mathrm{Hg})$ & $47 \pm 2$ \\
$\mathrm{MAP}(\mathrm{mm} \mathrm{Hg})$ & $100 \pm 21$ \\
Heart rate (beats/min) & $58 \pm 8$ \\
Epidural solution (mL) & $32 \pm 8$ \\
Operative time (min) & $96 \pm 29$ \\
VAS & $1.4 \pm 0.2$
\end{tabular}

Values are expressed as means \pm SD. Blood samples were taken at every 15 minutes during the operation.

$\mathrm{SVO}_{2}$, Arterial oxygen saturation; MAP, mean arterial pressure; $V A S$, visual analog score $(0=$ no pain, $10=$ worst possible pain).

minimally invasive direct $\mathrm{CABG}$ procedure was used to revascularize the LAD in 32 patients by using the rib cage lifting technique. ${ }^{10}$ In 63 patients a partial $(n=17)$ or complete median sternotomy $(n=46)$ was used. In all operations 5000 IU of heparin was used for anticoagulation, which was reversed with protamine at the termination of the operation. Cardiopulmonary bypass was not used. All patients received at least one ITA graft. Fifty-one additional radial artery grafts were used, 42 as an extension graft in the H-graft procedures. All proximal anastomoses were performed on the ITA pedicles.

There were 3 hybrid procedures as surgical LAD revascularization and percutaneous revascularization of the circumflex system. One patient had a concomitant $\mathrm{H}$-graft procedure to the LAD and carotid endarterectomy.

\section{Results}

In all patients in whom an epidural catheter was inserted, objectives of epidural anesthesia were achieved. Block level ranged between C6-T8 levels. Horner syndrome developed in 71 patients. One of these patients had unilateral Horner syndrome. There were no complications related to epidural anesthesia. Eleven patients required additional doses of local anesthetics at the jugular notch $(n=4)$ or xiphoid process $(n=7)$ level.

There was no mortality or major morbidity. Perioperative variables are depicted in Table 1.

\section{Pneumothorax}

In 39 (28.4\%) patients pneumothorax was observed during surgical intervention. In 13 patients primary repair of the defect in the pleura and catheter aspiration of the air in the pleural space was carried out. In 22 patients the pleural defect was opened widely, and the lung was allowed to collapse.

\section{Conversions}

Four patients were converted to general anesthesia because of respiratory distress caused by pneumothorax. One patient undergoing an $\mathrm{H}$-graft operation was converted to general anesthesia and median sternotomy for a conventional CABG because of a deeply intramyocardial LAD. One 


\section{TABLE 2. Same-day hospital discharge criteria}

- Patient demand

- Technically flawless operation

- Postoperative blood loss $<150 \mathrm{~mL} / 4 \mathrm{~h}$

- No evidence of myocardial ischemia on 12-lead echocardiography

- Stable hemodynamics

- No pain after discontinuation of epidural block

- Flawless assisted mobilization at the first postoperative hour

- Flawless nonassisted mobilization at the fourth postoperative hour

- Negative transthoracic echocardiography at the sixth postoperative hour

- Hospital discharge at the sixth postoperative hour

hundred thirty-two (96.3\%) of 137 patients completed the procedure awake.

Mean length of hospitalization was 1 day (range, 0-3 days). Seventy-nine patients stayed in the intensive care unit (ICU) overnight, and in 58 patients the ICU was not used. Eight patients were discharged from the hospital on the day of their operation (Table 2). No patient had in-hospital atrial fibrillation or readmission because of atrial fibrillation in the first postoperative month. Apart from the converted cases, 2 patients were lost to follow-up. One hundred thirty-one patients were followed up for a period of 3 months to 3 years postoperatively (mean, $17.4 \pm 7.2$ months). Of the patients, $94.7 \%$ were symptom free. Follow-up angiograms were obtained at the first postoperative day in 29 patients, at the first postoperative month in 5 patients, and between 7 and 26 months after the operation in 7 patients. Graft patency was $100 \%$ with one radial artery graft spasm. There were 3 new native coronary artery stenoses, which required a percutaneous revascularization procedure. The subgroup of patients who were discharged from the hospital on the same day of their operation were followed up very closely. Follow-up of this subgroup of patients were 100\% and ranged between 6 and 17 months (mean, $12.1 \pm 3.1$ months). Each patient had a transthoracic echocardiographic evaluation at the first and second postoperative months, and the first 5 patients had a follow-up coronary angiogram at the first postoperative month, which revealed no abnormality.

\section{Discussion}

High thoracic epidural anesthesia might have beneficial effects in beating-heart surgery, with or without general anesthesia. ${ }^{11}$ Thoracic epidural block yields cardiac sympathectomy, which has distinct advantages in patients with ischemic heart disease. ${ }^{11,12}$ Also, bradycardia and coronary vasodilatation facilitates beating-heart surgery technically, and ITA dilatation, which is observed with blockage at the C6 level, provides excellent graft flow. Moreover, epidural anesthesia provokes a fibrinolytic state that might counter- balance the procoagulant state observed after beating-heart surgery. ${ }^{13,14}$ Another advantage of sensory block of the chest is superb pain control, which makes the immediate postoperative period virtually painless.

Although there is evidence that thoracic epidural anesthesia in conjunction with general anesthesia has no effect on the occurrence of atrial fibrillation after $\mathrm{CABG},{ }^{15}$ the absence of readmission for atrial fibrillation in the presented series of patients requires further investigation. It is also noteworthy that there is no reported case of postoperative atrial fibrillation in the awake CABG setting. ${ }^{2-7}$

A relative disadvantage of epidural anesthesia is the inability to insert the epidural catheter in place in about 3\% of patients. Patients with very tight or calcified intervertebral spaces are most prone to this. Three of 4 patients in whom an epidural catheter could not be inserted in the presented series had ankylosing spondylitis.

Contrary to our previous experience, ${ }^{1}$ aspirin is no longer discontinued before off-pump coronary artery surgery, irrespective of whether epidural anesthesia is used. The major drawback of high thoracic epidural anesthesia is the risk of epidural hematoma formation, which is estimated to be 1 in $150,000 .{ }^{16}$ This complication can be avoided by strict adherence to such principles as a minimum time delay of 60 minutes between epidural puncture and heparinization and willingness to postpone surgical intervention for at least 24 hours if a bloody tap occurs. ${ }^{3}$ Adherence to these principles is especially important in patients with end-stage liver disease, in whom abnormal blood coagulation profiles are frequently encountered. In these patients the T1-T2 interval should be selected for epidural catheter insertion, where the likelihood of a bloody tap is minimal with a proper insertion technique.

The epidural anesthesia solution itself exerts a sedative effect on the patients, and no additional sedation is necessary throughout the operation, except for premedication with a small doze of midazolam. We have not observed anxiety or lack of cooperation in any of our patients. In fact, maintenance of patient response is very important during epidural anesthesia to monitor the development of Horner syndrome, which occurs when the block reaches the C6 level. This is a very important safety mark in the spontaneously breathing awake patient. As the epidural block paralyzes the intercostal muscles, maintenance of diaphragmatic respiration is mandatory. Diaphragm paralysis, which occurs at the $\mathrm{C} 4$ level, can be avoided by monitoring the development of Horner syndrome, indicating a block at the C6 level. We have not observed a block level of greater than C6 in any of our patients. Diaphragmatic respiration was adequate in maintaining sufficient levels of oxygenation (Table 1). A moderate accumulation of carbon dioxide was noted without clinical significance. Avoidance of a re- 
breathing mask and decreasing the dose of epidural anesthetic solution is sufficient to deal with hypercarbia.

Because this surgical strategy involves operating on patients who are on spontaneous respiration, occurrence of pneumothorax during surgical operation was a dreaded complication in the beginning of this series. Initially, we were concerned about opening the pleural cavity and had devised methods to prevent it. ${ }^{1}$ When the pleural cavity was opened inadvertently, this was through a small opening in the pleura, and there was a stable period of about 5 to 6 minutes before respiratory distress and vigorous cardiac motion started, which was observed consistently in every patient in whom the pleura was opened. This stable period of time was sufficient to repair the defect and aspirate the air in the pleural cavity in almost all patients, resulting in a very low conversion rate. Later in our experience, however, we discovered that the main factor causing respiratory distress was not the pneumothorax itself but rather the to-and-fro air flow through the small opening in the pleura, resulting in tension in the pleural cavity. When the left pleura was opened wide, high-velocity airflow through a small opening was avoided, and this was well tolerated by the patients without significant changes in respiratory parameters.

Our current strategy is to use surgical techniques to decrease the probability of opening the pleura in every patient with or without median sternotomy. When pneumothorax is encountered, initially we try to repair the defect and aspirate the air in the pleural cavity, and if not sufficient, we open the pleura wide.

Median sternotomy is well tolerated in all patients after thoracic epidural anesthesia, although some patients might require supplementary doses of local anesthetics at the jugular notch or xiphoid level. No patient in our series was converted to general anesthesia because of intolerance to median sternotomy in the awake setting. The ability to perform off-pump coronary surgery in the awake patients through a median sternotomy essentially makes it feasible to perform any off-pump surgery during epidural anesthesia. The majority of the presented series are single-vessel operations. Although our current experience is very limited in lateral wall revascularization, it might expand in the near future with the advent of new exposure devices for offpump coronary surgery. This strategy might offer the benefits of CABG to patients who are deemed inoperable in regard to general anesthetic considerations.

Avoidance of general anesthesia enables mobilization of patients immediately after surgical intervention to a great extent. ${ }^{6}$ After a flawless operation, hemodynamically stable patients can be transferred to the ward with careful observation. In the presented series of patients, 58 patients were transferred to the ward after a brief period of observation for stability without ICU experience. Avoidance of ICU expe- rience in selected patients is not only beneficial for effective use of hospital resources but also contributes significantly to patient satisfaction after CABG. ${ }^{6}$ Eight of these patients, who were very carefully selected, were discharged from the hospital the afternoon of their coronary bypass surgery without any adverse outcome. Although this experience proves the safety and feasibility of same-day discharge after coronary bypass in highly selected patients, further studies are needed to define which category of patients are to be candidates for ambulatory coronary bypass surgery. Also, further studies are required to define the possible extent and limitations of cardiac surgery under high thoracic epidural anesthesia.

\section{References}

1. Karagoz HY, Sonmez B, Bakkaloglu B, et al. Coronary artery bypass grafting in the conscious patient without endotracheal general anesthesia. Ann Thorac Surg. 2000;70:91-6.

2. Zenati MA, Paiste J, Williams JP, Strindberg G, Dumouchel JP, Griffith BP. Minimally invasive coronary bypass without general endotracheal anesthesia. Ann Thorac Surg. 2001;72:1380-2.

3. Paiste J, Bjerke RJ, Williams JP, Zenati MA. Minimally invasive direct coronary artery bypass surgery under high thoracic epidural. Anesth Analg. 2001;93:1486-8.

4. Anderson MB, Kwong KF, Furst AJ, Salerno TA. Thoracic epidural anesthesia for coronary bypass via left anterior thoracotomy in the conscious patient. Eur J Cardiothorac Surg. 2001;20:415-7.

5. Aybek T, Dogan S, Kessler P, et al. Complete arterial surgical revascularization through median sternotomy in awake patients. $Z$ Kardiol. 2002;91:238-42.

6. Aybek T, Dogan S, Neidhard G, et al. Coronary artery bypass grafting through complete sternotomy in conscious patients. Heart Surg Forum. 2002;5:17-21.

7. Vanek T, Straka Z, Brucek P, Widimsky P. Thoracic epidural anesthesia for off pump coronary artery bypass without intubation. Eur J Cardiothorac Surg. 2001;20:858-60.

8. Cohn WE, Suen HC, Weintraub RM, Johnson RG. The "H" graft: an alternative approach for performing minimally invasive direct coronary artery bypass. J Thorac Cardiovasc Surg. 1998;115:148-51.

9. Coulson AS, Bakhshay SA. The T-midcab procedure: use of extension grafts from the undisturbed internal mammary artery in high risk patients. Heart Surg Forum. 1998;1:54-9.

10. Karagoz HY, Kurtoglu M, Ozerdem G, Battaloglu B, Korkmaz S, Bayazit K. Minimally invasive coronary artery bypass grafting: the rib cage lifting technique. J Thorac Cardiovasc Surg. 1998;116:354-6.

11. Riedel BJ, Wright IG. Epidural anesthesia in coronary artery bypass grafting surgery. Curr Opin Cardiol. 1997;12:515-21.

12. Ganapathy S, Murkin JM, Dobkowski W, Boyd D. Stress and inflammatory response after beating heart surgery versus conventional bypass surgery: the role of thoracic epidural anesthesia. Heart Surg Forum. 2001;4:323-7.

13. Mariani MA, Gu YJ, Boonstra PW, Grandjean JG, van Oeveren W, Ebels T. Procoagulant activity after off-pump coronary operation: is the current anticoagulation adequate? Ann Thorac Surg. 1999;67: 1370-5.

14. Rosenfeld BA, Beattie C, Christopherson R, et al. The effects of different anesthetic regimens on fibrinolysis and the development of postoperative arterial thrombosis. Anesthesiology. 1993;79:435-43.

15. Jideus L, Joachimsson PO, Stridsberg M, et al. Thoracic epidural anesthesia does not influence the occurrence of postoperative sustained atrial fibrillation. Ann Thorac Surg. 2001;72:65-71.

16. Vandermeulen EP, Aken HV, Vermylen J. Anticoagulants and spinalepidural anesthesia. Anesth Analg. 1994;79:1165-77. 